\title{
Determination of antibody levels to Candida albicans in healthy and hospitalised adults using a radioimmunoassay
}

\author{
SUSAN J. COBB AND D. PARRATT \\ From the Department of Bacteriology and Immunology, Western Infirmary, Glasgow G11 6NT, UK
}

SUMmaRY A radioimmunoassay for antibody to Candida albicans is described. The test uses whole, killed organisms as the antigen and radiolabelled sheep anti-human globulins to quantitate different classes of antibody to $C$. albicans. The assay has been compared with an Ouchterlony precipitin method and found to be simpler, more rapid, and more sensitive than the latter. Results obtained from two groups of symptomless adults indicated that the range of antibody level was wider for a hospitalised group than for a group of blood transfusion donors, particularly in respect of IgG and IgA antibody. The reason for the increase of antibody in hospital patients was not clear but may have been related to antibiotic therapy. The difficulties in interpretation of Candida serology have therefore been re-assessed in the light of more detailed knowledge of the range and type of antibody to be expected in normal individuals.

Candida albicans infection presents many problems in clinical practice. Most notable of these is the distinction between serious organ infection involving, for example, the lung or oesophagus and simple colonisation of these sites. This distinction is difficult to make by cultural examination, although the demonstration of mycelial forms in the specimen or biopsy material has been regarded as an important indication of infection (Winner, 1969). Recently, it has been suggested that the demonstration of serum antibody to mycelial rather than blastospore antigens, using a fluorescent antibody method, is a simpler and more sensitive way of detecting deep tissue infection (Ho et al., 1976). Heavy colonisation of the mouth, pharynx, gut, and urinary tract by the organism is now commonly seen in patients receiving broad-spectrum antibiotics (Seelig, 1966) and the progress of the colonisation requires careful monitoring if deep tissue infection or septicaemia are to be avoided.

We here describe a radioimmunoassay (RIA) for the quantitation of antibody to $C$. albicans which is simple, accurate, and sensitive, and which has been specifically designed to enable the clinician to follow the humoral immune response during increased colonisation by the organism. In this initial communication we report the results of antibody

Received for publication 17 May 1978 quantitation for a group of healthy adults and for a selected group of hospitalised adults. The RIA has also been compared with the Ouchterlony double diffusion precipitin test which has, in the past, been the most widely used serological method for the diagnosis of candidiasis.

\section{Material and methods}

\section{ANTIGEN}

C. albicans was obtained from the throat of a healthy individual by standard cultural methods. The organism produced a positive germ tube result within three hours and showed typical streak formation on cornmeal agar after 24 hours at room temperature $\left(20^{\circ} \mathrm{C}\right)$. A stock culture was maintained on peptone-agar slopes with periodic subculture. For antigen preparation the organism was cultured on brain-heart infusion agar for 84 hours at $37^{\circ} \mathrm{C}$, the growth being harvested mechanically, suspended in $0.15 \mathrm{M} \mathrm{NaCl}$, and killed by heating at $70^{\circ} \mathrm{C}$ for one hour. The yeast cells were then washed thrice with $0.15 \mathrm{M} \mathrm{NaCl}$. After washing, a $20 \%$ (v/v) working suspension was prepared in $0.15 \mathrm{M} \mathrm{NaCl}$.

\section{ANTISERA}

Sheep anti-human IgG and sheep anti-human IgA were available from laboratory stock and were checked for heavy chain specificity by testing against 
chromatographically purified human IgG, IgA, and IgM using standard immunoelectrophoretic techniques. Rabbit anti-human IgM was obtained commercially (Wellcome Reagents Ltd). $200 \mathrm{mg}$ anti-IgG, $60 \mathrm{mg}$ anti-IgA, or $40 \mathrm{mg}$ anti-IgM globulin preparations (obtained by precipitation with $36 \%$ w/v $\mathrm{Na}_{2} \mathrm{SO}_{4}$ ) were radiolabelled with 0.5-1.0 mCi iodine-125 (125I) (IMS 30, Amersham Ltd) by the chloramine $\mathrm{T}$ method of McConahey and Dixon (1966). Free (non protein-bound) 125I was separated by chromatography using Sephadex G-25 (Pharmacia Ltd).

SAM PLES OF SERUM

(A) A collection of $\mathbf{4 0}$ sera from blood transfusion donors in the West of Scotland was supplied by the Strathclyde Regional Blood Transfusion Unit. The age and sex of the donors were not known.

(B) Forty sera were obtained from the Haematology Department, Western Infirmary, Glasgow from inpatients who had required blood grouping and cross-matching. This group of sera was selected from patients between the ages of 18 and 65 years, and sera from seriously ill patients were not included. In the majority of instances, cross-matching had been carried out as a prelude to elective surgery.

(C) The standard serum used for RIA was a $250 \mathrm{ml}$ donation from a patient recently recovered from pulmonary candidiasis. This serum was stored in $1 \mathrm{ml}$ aliquots.

The amount of antibody of the different classes in the standard serum was estimated in weight units by quantitative agglutination according to the method described by Nielsen et al. (1973). After the final elution of the antibody, the quantitation of the various classes of immunoglobulin was achieved by Mancini assay using low-level Immunoplates (Hyland Ltd). The standard serum was found to contain $154 \mu \mathrm{g} / \mathrm{ml} \mathrm{IgG} \mathrm{antibody,} 39 \mu \mathrm{g} / \mathrm{ml} \mathrm{IgM}$ antibody, and $57 \mu \mathrm{g} / \mathrm{ml} \mathrm{IgA}$ antibody.

(D) Seventy-four sera were used for comparison of an Ouchterlony precipitin test and the RIA, and these were from patients in the Western Infirmary, Glasgow. The sera had been received for routine assay of candida antibody. This group included patients without any clinical evidence of candidiasis, patients with chronic mucocutaneous candidiasis, and patients with either organ infection or colonisation of multiple sites. All sera were stored at $-20^{\circ} \mathrm{C}$ until used.

RADIOIMMUNOASSAY

The method was modified from the technique described by Nielsen et al. (1973). A standard curve was obtained in the first instance by adding aliquots of the standard serum neat and at doubling dilutions up to 1 in 16 to aliquots of $C$. albicans suspension, contained in $70 \times 12 \mathrm{~mm}$ plastic tubes. After mixing, the contents were incubated for 30 minutes at room temperature and washed thrice with $0.15 \mathrm{M} \mathrm{NaCl}$. An aliquot of radiolabelled antiglobulin (of appropriate specificity) was then added to each tube, and the incubation and washing procedures were repeated, after which the radioactivity remaining in the cell pellets was measured using an ICN Gammaset gamma counter. Control tubes containing only antigen suspension and radiolabelled antiglobulin were included in the test to provide a measure of non-specific binding of the latter to the organism. From the results with the standard serum it was possible to adjust the quantities of antigen or antiglobulin to provide conditions of excess of each of these components, in the manner described by Nielsen et al. (1973). Typically, it was found that $200 \mu \mathrm{l} C$. albicans suspension contained an excess of antigen for $100 \mu \mathrm{l}$ of the standard serum, and an excess of antiglobulin was contained in $125 \mu \mathrm{l}$ aIgG, $75 \mu \mathrm{l}$ aIgA, or $75 \mu \mathrm{l}$ aIgM solution. Thereafter assays of unknown samples were performed simultaneously with assays of dilutions of the standard serum and controls, to provide a direct quantitation of the antibody content of the unknown samples. Since the antibody content of the standard serum had been calculated in weight units it was possible to determine the weight of IgGe $\operatorname{IgA}$, and IgM antibody in each test sample. Bovine serum albumin $(0 \cdot 1 \% \mathrm{w} / \mathrm{v})$ was added to the washing solution in assays of $\operatorname{IgM}$ and $\operatorname{IgA}$ antibody to lower the non-specific binding of the antiglobulin to the organism.

OUCHTERLONY DOUBLE-DIFFUSION

PRECIPITIN TEST

The antigen used was prepared from $30 \mathrm{ml}$ of a $20 \%$ suspension of $C$. albicans obtained as for RIA (see above). The organism was disrupted by several freeze/thaw cycles or mechanically in a Braun disintegrator. After centrifugation, the supernatant was removed and concentrated to approximately $18 \mathrm{ml}$ by dialysis against Carbowax. This concentrate, neat and diluted 1 in 10 , produced several precipitin arcs with sera known to have high levels of antibody to $C$. albicans.

The precipitin tests were performed in $1 \%$ Ion agar (Oxoid) poured to a depth of $4 \mathrm{~mm}$ in plastic Petri dishes. A central well of $5 \mathrm{~mm}$ diameter contained the antigen and was surrounded at a distance of $3.5 \mathrm{~mm}$ by six $5 \mathrm{~mm}$ wells, equidistant from each other, which contained the test sera. The wells were filled to the brim. After 48 hours' incubation at room temperature precipitin lines were observed, the plates were then washed for seven days with several 
changes of $0.15 \mathrm{M} \mathrm{NaCl}$, dried, and stained with Amido Schwartz $(1.5 \% \mathrm{w} / \mathrm{v})$ made up in a water: ethanol:acetic acid mixture $(1: 4 \cdot 5: 4 \cdot 5 \mathrm{v} / \mathrm{v})$ containing $1 \%$ glycerol. After decolorisation in the same solvent each specimen was re-examined for precipitin lines.

\section{Results}

\section{RADIOIMMUNOASSAY}

As can be seen from Figs 1 and 2, the ranges of antibody levels in the hospitalised group and blood transfusion donors are not comparable. It is evident that the hospitalised group were abnormal with respect to antibody production to $C$. albicans. The majority of blood transfusion donors had IgG, IgA, and IgM antibody levels of less than $45 \mu \mathrm{g} / \mathrm{ml}$, whereas many of the hospitalised group had IgG and IgA antibody levels above this value. Thus it appeared that some individuals within this category had been stimulated to produce antibody. The difference in the distribution of IgM antibody levels was not as great, although comparison of Figs 1 and 2 does reveal a slight change of the same type. A few individuals within each group had very high levels of $C$. albicans antibody.

The finding of a high IgG antibody level (that is, $>45 \mu \mathrm{g} / \mathrm{ml}$ ) was not always associated with high IgA or IgM antibody levels. Nevertheless, in $84 \%$ of

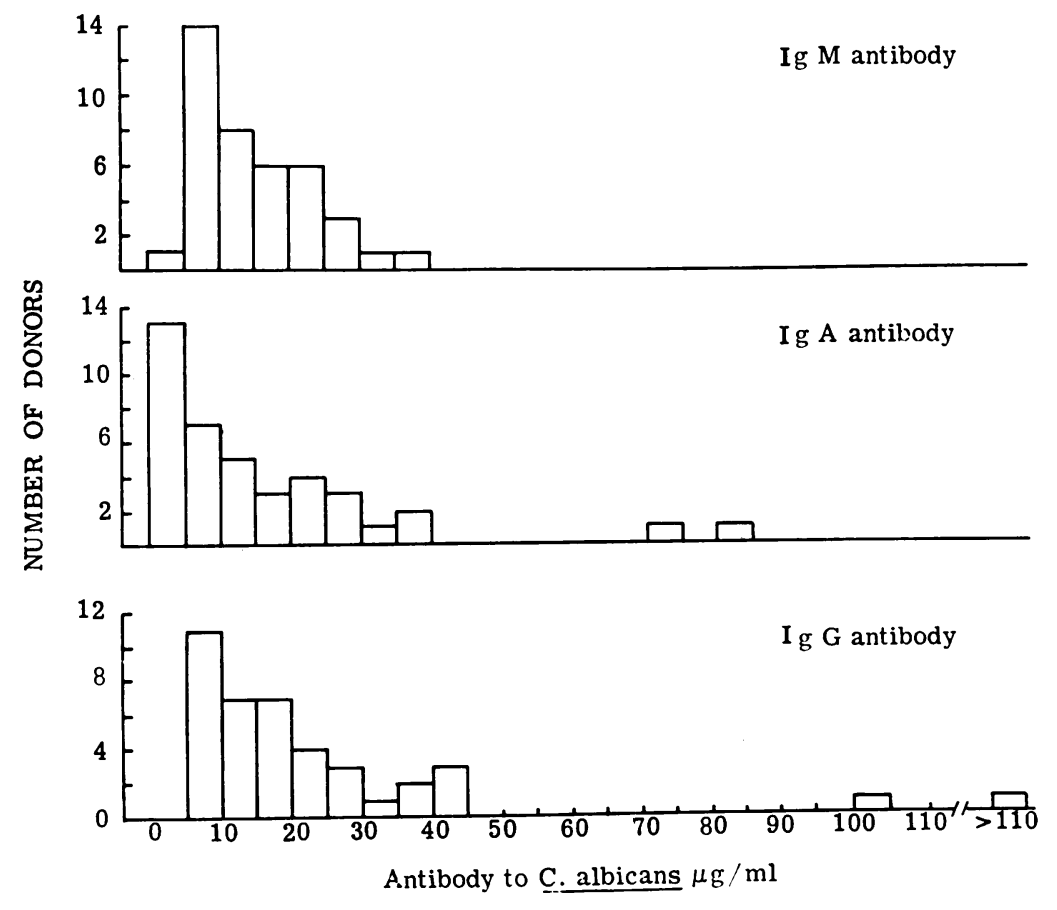

the blood transfusion donors, the IgG, IgA, and IgM antibody levels were at the same point in the distribution (that is, below mean, at mean, or above mean) of each immunoglobulin class. A similar association held for $78 \%$ of the hospitalised group. It follows that in the latter group the production of antibody was not confined to particular immunoglobulin classes, in the majority of instances.

\section{COMPARISON OF RIA AND PRECIPITIN TEST}

Figure 3 shows the results of the RIA of IgG antibody and the precipitin test of 74 consecutive sera submitted to the laboratory for routine estimation of C. albicans antibody. In general, it appeared that antibody levels greater than $100 \mu \mathrm{g} / \mathrm{ml}$ were associated with a positive precipitin test, although 11 sera had antibody levels higher than this and were not precipitin positive. The majority of sera with levels within the ranges depicted for the blood transfusion and hospital inpatient groups ( $<100 \mu \mathrm{g} / \mathrm{ml}$ ) were precipitin negative. Also, it is clear from Fig. 3 that a positive precipitin test can be associated with a wide range of $C$. albicans levels, with as much as a 14-fold difference between the highest and lowest levels. The results also indicate the improved serological analysis achieved by the RIA and its greater sensitivity compared with the precipitin test.

Fig. 1 Distribution of serum antibody levels to $\mathrm{C}$. albicans in blood transfusion control donors. 


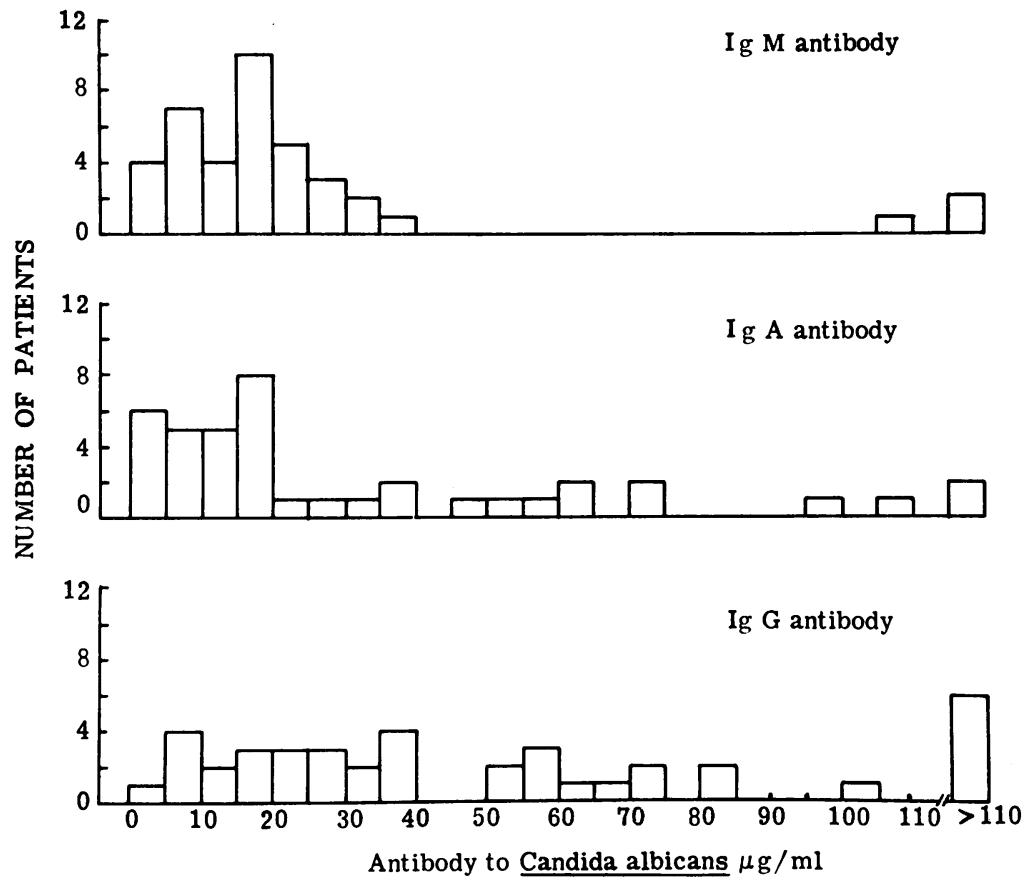

Fig. 2 Distribution of serum antibody levels to $\mathrm{C}$. albicans in hospitalised patients.

\section{Discussion}

Candida albicans is found as a normal commensal of the oropharynx and as a pathogen in this site and in the vagina, urinary tract, and skin. In addition, organ and deep tissue infections, although less common, are serious and may lead to septicaemia, which is frequently fatal. The difficulty of diagnosis is that isolation of the organism only rarely indicates infection while biopsy to demonstrate tissue invasion can be justified only in certain circumstances. Frequently, therefore, diagnosis has to be by serological means. Agglutination (Preisler et al., 1969), fluorescent antibody (Lehner, 1966), and crossed immunoelectrophoresis (Axelsen et al., 1974; Odds et al., 1975) tests have been used for this purpose, although the most widely used procedures are probably the double gel diffusion precipitin (Ouchterlony) and immunoelectrophoresis tests. The rationale for any of these procedures is that infection in contradistinction to colonisation will stimulate candida antibody production, which can then be detected and, in some instances, quantitated. There is, however, evidence that high levels of antibody frequently exist in healthy individuals. For example, Chew and Theus (1967) found precipitins in the sera of $48 \%$ of normals, and Axelsen et al. (1974) in at least $90 \%$. In another investigation, Stallybrass (1964) could not detect pre- cipitins in any normal controls. The situation is therefore confusing. Axelsen (1976), reviewing the problem of serology in candidiasis, concluded that efficient tests should be quantitative rather than qualitative and should be standardised.

Having found a solid phase RIA for quantitation of the antibody in farmer's lung (Parratt et al., 1975) to be preferable to other serological techniques, including a precipitin method, we applied the same principle to the measurement of $C$. albicans antibody.

Before any patient-orientated investigations we attempted to establish the range of candida antibody in healthy blood transfusion donors. All of this group had detectable IgG antibody, at levels greater than $5 \mu \mathrm{g} / \mathrm{ml}$; the majority had IgM levels greater than $5 \mu \mathrm{g} / \mathrm{ml}$, but half the group demonstrated little or no IgA antibody $(<5 \mu \mathrm{g} / \mathrm{ml})$. Excluding the latter, the distribution of levels was similar for each immunoglobulin class of antibody, ranging to $45 \mu \mathrm{g} / \mathrm{ml}$, with only occasional sera beyond this value (Fig. 1). These findings support the view of Axelsen (1976) that candida antibody is present in the serum of all individuals if an appropriate test is used for its detection. Indeed, the variability of antibody levels suggests that different individuals might be responding to different amounts of $C$. albicans (presumably commensal in the gastrointestinal tract and oropharynx) or be responding in 


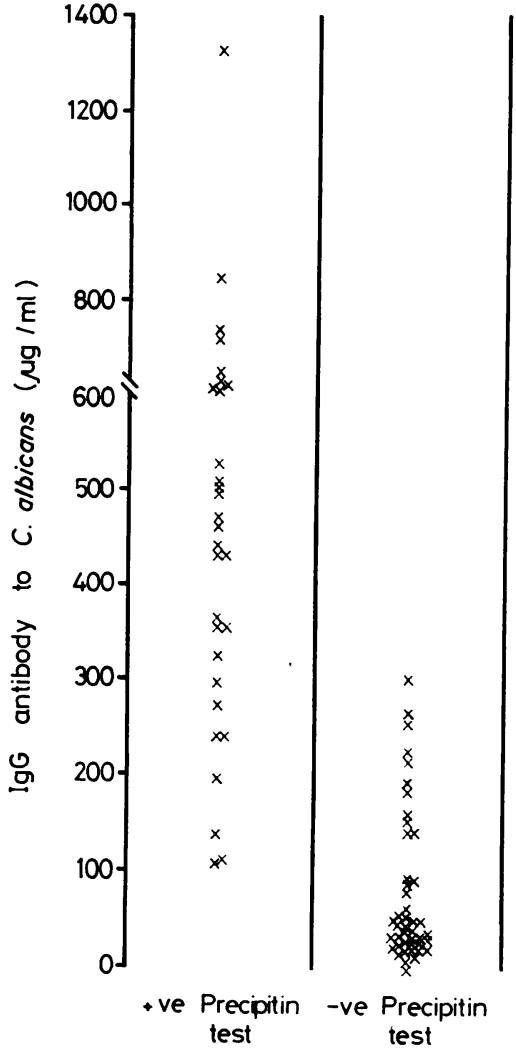

Fig. 3 Comparison of IgG antibody levels to C. albicans with precipitin test results.

different degree to similar amounts of the organism.

Patients in the hospitalised group had a wider range of IgG and IgA antibody levels, and high levels were found more frequently. IgM antibody levels showed a similar distribution in both groups although several very high values were recorded in the inpatient group. A retrospective analysis of the case records of all the patients in this group did not reveal with certainty any single factor that could have accounted for the increased antibody levels. Thus the length of hospital stay, age, sex, intercurrent illness, and antibiotic therapy seemed unrelated, and none of the patients had, or developed, overt candidiasis.

Nevertheless, we suspect that antibiotics were responsible for increasing each patient's candida load and, in response, their antibody level to the organism. In other investigations (unpublished) we have shown that small amounts of antibiotic administered to healthy volunteers can increase both of these parameters. It may be that a hospitalised patient, even if not receiving prescribed antibiotics, has sufficient contact with the drugs to bring about the effects we have described. Certainly the difference between the two groups is important, for it illustrates that a high antibody level may be only a reflection of the change of environment (that of outpatient to inpatient) and cannot be unequivocally regarded as a sign of invasion by $C$. albicans. It is difficult therefore to decide whether to use the distribution for the inpatient or outpatient group as the 'normal range', and we are therefore of the opinion that single estimations of antibody level in any patient are unsatisfactory as the patient's circumstances must be taken into account when trying to assess the significance of the result.

It is clear that the RIA is more sensitive as a serological method than the conventionally used precipitin test (Fig. 3). The group of sera used in this part of the study included patients with heavy colonisation, deep tissue (usually pulmonary) candidiasis, and chronic mucocutaneous candidiasis. Sera with IgG candida antibody levels over $300 \mu \mathrm{g} / \mathrm{ml}$ always gave a positive precipitin test, and, conversely, all sera with levels below $100 \mu \mathrm{g} / \mathrm{ml}$ were precipitin negative. Within the range $100-300 \mu \mathrm{g} / \mathrm{ml}$ some sera were precipitin positive and some negative. The comparison was made between precipitin results and IgG antibody because analogous data of our own (unpublished) and of Hollingdale (1974) have shown IgG to be the important reactant in precipitin tests. From the comparison of the IgG antibody levels and precipitin test it is evident that the patients with moderate levels of antibody gave no consistent precipitin test results, thereby indicating the lack of sensitivity of this technique.

From our own data (unpublished) it is known that many patients with candida infections have IgG antibody levels in the range $100-300 \mu \mathrm{g} / \mathrm{ml}$, but from Figs 1 and 2 it is evident that $17.5 \%$ of the hospitalised adults and $5 \%$ of the blood transfusion donors also had antibody levels within this range. Thus it is evident that there is a large overlap in the levels of antibody found in healthy, colonised, and infected adults, and in this situation no single level of antibody can be used as a diagnosis of infection. We believe that the only satisfactory method of assessing the individual's status is to measure antibody levels over a period of time to detect any changes. The RIA is ideally suited to this purpose on account of its reproducibility $( \pm 9 \%$ for $\mathrm{IgG}$; $\pm 12 \% \mathrm{IgM} ; \pm 16 \% \mathrm{IgA})$, which allows accurate definition of the antibody response over short intervals, thereby avoiding delays in diagnosis. In practice, it has been possible to detect increased reactivity to the organism within 48 hours of the onset of heavy colonisation or deep tissue invasion. and studies are in progress to determine whether the 
distinction between these two states can be predicted by this kind of careful serological analysis.

In the present work the RIA has provided essential quantitative information on the distribution of antibody in normal and abnormal situations and therefore offers not merely a means of serological diagnosis but a simple technique to study the interplay between host and organism during normal colonisation, over-colonisation, and infection states.

We acknowledge the assistance given by the staff of the Western Infirmary Blood Transfusion Unit and the Regional Blood Transfusion Unit, Law Hospital, in providing sera for this study. In addition, we thank Dr G. Boyd, Respiratory Investigation Unit, Glasgow Royal Infirmary for supplying patients' sera for use as standard and test samples.

\section{References}

Axelsen, N. H. (1976). Analysis of human Candida precipitins by quantitative immunoelectrophoresis: a model for analysis of complex microbial antigenantibody systems. Scandinavian Journal of Immunology, 5, 177-190.

Axelsen, N. H., Kirkpatrick, C. H., and Buckley, R. H. (1974). Precipitins to Candida albicans in chronic mucocutaneous candidiasis studied by crossed immunoelectrophoresis with intermediate gel. Correlation with clinical and immunological findings. Clinical and Experimental Immunology, 17, 385-394.

Chew, W. H., and Theus, T. L. (1967). Candida precipitins. Journal of Immunology, 98, 220-224.

Ho, Y. M., Ng, M. H., Teoh-Chan, C. H., Yue, P. C. K., and Huang, C. T. (1976). Indirect immunofluorescence assay for antibody to germ tube of Candida albicans-a new diagnostic test. Journal of Clinical Pathology, 29, 1007-1010.

Hollingdale, M. R. (1974). Antibody responses in patients with farmer's lung disease to antigens from Micropolyspora faeni. Journal of Hygiene, 72, 79-89.

Lehner, T. (1966). Immunofluorescence study of Candida albicans in candidiasis, carriers and controls. Journal of Pathology and Bacteriology, 91, 97-104.

McConahey, P. J., and Dixon, F. J. (1966). A method of trace iodination of proteins for immunologic studies. International Archives of Allergy and Applied Immunology, 29, 185-189.

Nielsen, K. H., Parratt, D., and White, R. G. (1973). Quantitation of antibody to particulate antigens using a radiolabelled anti-immunoglobulin reagent: application to estimation of antibody in farmer's lung syndrome. Journal of Immunological Methods, 3, 301-313.

Odds, F. C., Evans, E. G. V., and Holland, K. T. (1975). Detection of Candida precipitins: a comparison of double diffusion and counter immunoelectrophoresis. Journal of Immunological Methods, 7, 211-218.

Parratt, D., Nielsen K. H., Boyd, G., and White, R. G. (1975). The quantitation of antibody in farmer's lung syndrome using a radioimmunoassay: results of a clinical survey and comparison of three serological methods. Clinical and Experimental Immunology, 20, 217-225.

Preisler, H. D., Hasenclever, H. F., Levitan, A., and Henderson, E. S. (1969). Serologic diagnosis of disseminated candidiasis in patients with acute leukemia. Annals of Internal Medicine, 70, 19-30.

Seelig, M. S. (1966). The role of antitiotics in the pathogenesis of Candida infections. American Journal of Medicine, 40, 887-917.

Stallybrass, F. C. (1964). Candida precipitins. Journal of Pathology and Bacteriology, 87, 89-97.

Winner, H. I. (1969). The transition from commensalism to parasitism. British Journal of Dermatology, 81, Supplement, 1, 62-68.

Requests for reprints to: Dr S. J. Cobb, University Department of Bacteriology and Immunology, Western Infirmary, Glasgow, G11 6NT, UK. 